\title{
Association Between Elevated HbA1c Levels and Urinary Tract Infection Among Diabetic Women
}

\author{
Ibrahim Olayemi Abdul ${ }^{1}$; Favour Osazuwa ${ }^{2, *}$; Dirisu Osilume ${ }^{3}$ \\ ${ }_{1}$ Immunology and Chemical Pathology Laboratory, Nena Hospital, Lugbe, Abuja, Nigeria \\ ${ }_{2}^{2}$ Department of Laboratory, Lily Hospitals Limited, Warri, Delta State, Nigeria \\ ${ }^{3}$ Department of Medical Laboratory Sciences, Nnamdi Azikiwe University, Awka, Nigeria \\ *Corresponding author: Favour Osazuwa, Department of Laboratory, Lily Hospitals Limited, Warri, Delta State, Nigeria. E-mail: osazuwafavour@yahoo.com
}

Received: May 18, 2014; Accepted: August 15, 2014

\begin{abstract}
Background: Urinary tract infection is one of the common clinical sequelae of diabetes mellitus.
Objectives: This study aimed to determine the effect of poor glycaemic control as determined by glycated hemoglobin (HbAic) levels on the prevalence of urinary tract infections among diabetic women.

Materials and Methods: In this cross-sectional descriptive study, 50 non-pregnant diabetic women attending the diabetes clinic of Nena hospital, Abuja, Nigeria were included as subjects and 25 age and sex-matched apparently healthy individuals were included as controls. Results: Mean HbAic levels in diabetic women were significantly higher than in healthy controls $(7.29 \pm 2.4 \%$ vs. $4.5 \pm 1.8 \%)(\mathrm{P}<0.001)$. The prevalence of poor glycaemic control was high; 19 (38\%) and UTI was significantly more prevalent in DM patients with poor glycaemic control than in subjects with good glycaemic control 14 (77.8\%) vs. $4(22.2 \%)(\mathrm{P}<0.001)$.

Conclusions: HbA1c values showing poor glycaemic control may be a proxy indicator for screening for UTI among women with diabetes mellitus.
\end{abstract}

Keywords: Diabetes Mellitus; Urinary Tract Infection; Glycated Hemoglobin; Nephropathy

\section{Background}

Urinary tract infection (UTI) is a common finding among diabetic patients [1]. Evidence abounds that UTI is more common in female diabetics than in those without diabetes [2]. Diabetes is a risk factor for UTI because of its ability to cause defective host immune response to infection, and neutrophil dysfunction [3].

Glycated hemoglobin (HbA1c) is now used as a significant indicator and marker of poor glycaemic control which include prevalent retinopathy and nephropathy among diabetics [4]. HbA1c was initially identified as unusual hemoglobin in patients with diabetes over forty years ago [5]. HbA1c reflects average plasma glucose over the previous six to eight weeks [6]. Concentrations of blood levels of HbA1c among diabetes mellitus (DM) patients are increased when there is poor glycaemic control causing renal disease and predisposition to UTI [7].

\section{Objectives}

It is the aim of this study to determine if there is an association between poor glycaemic control and prevalent UTI among diabetic women.

\section{Patients and Methods}

This cross-sectional descriptive study included 50 fe- male DM patients attending the diabetes clinic of Nena hospital, Abuja, Nigeria. Twenty five sex and age matched non-diabetic apparently healthy individuals were included as controls. This study was carried out in the period January 2013 to July 2013. All study participants (both control and patients) were non-pregnant individuals. Patients already known to have diabetes were used for this study; patients were diagnosed as diabetic using the World Health Organization criteria [8]. Our diabetic clinic is estimated to currently have over 200 diabetic female patients on treatment, but only 50 gave consent and were included for this study. Data on demographics and age were collected with the aid of an administered check list. Informed consent was received from subjects before inclusion in the study. Ethical approval was received from Nena hospital ethical committee before commencement of this study.

\subsection{Sample Collection}

About $5 \mathrm{~mL}$ of venous blood was drawn aseptically into lithium heparin bottle and urine samples were collected by patients onto universal sterile container for urine microscopy and culture. Subjects were told specifically to pass midstream urine into the containers adhering to standard rules that prevent contamination. All sample

Copyright (C) 2015, Zahedan University of Medical Sciences. This is an open-access article distributed under the terms of the Creative Commons Attribution-NonCommercial 4.0 International License (http://creativecommons.org/licenses/by-nc/4.0/) which permits copy and redistribute the material just in noncommercial usages, provided the original work is properly cited. 
Olayemi Abdul I et al.

analysis was securely transported to the medical microbiology and chemical pathology laboratory for analysis.

\subsection{Glycated Hemoglobin (HbA1c) Quantification}

HbAic was quantified spectrophotometrically using HbA1c test kits (Agappe diagnostics, Kerala India). Briefly, hemolysate was prepared from heparin anticoagulant whole blood samples. The HbA1c fraction were then specifically eluted after washing away the HbAla $+\mathrm{b}$ fraction and quantified by direct photometric reading at $415 \mathrm{nM}$. Poor glycaemic control was defined as HbAic $<7.0 \%$ as recommended by the American Diabetes association [9].

\subsection{Urine Microbiology}

A loopful $(0.001 \mathrm{~mL})$ of centrifuged urine was streaked on to blood agar and cysteine lactose electrolyte deficient (CLED) medium. (Oxoid, Fisher Laboratories, United Kingdom). The plates were incubated aerobically at $37^{\circ} \mathrm{C}$ for 24 hours. About $10 \mathrm{~mL}$ of each well mixed urine sample was centrifuged at $2000 \mathrm{~g}$ for 5 minutes. The supernatant was discarded and a drop of the deposit was examined microscopically at high magnification for pus cells, red blood cells, epithelial cells, cast, crystals and yeast-like cells. Pus cells $\geq 5$ per high power field were considered significant to indicate infection. Urinary tract infection was diagnosed, if the bacteria or pus cell count, or both were significant in an individual.

\subsection{Statistical Analysis}

This was carried out using SPSS-16. The association between poor glycaemic control and UTI was assessed. A Pvalue $<0.05$ was said to be significant.

\section{Results}

The mean age of the study participants was $47 \pm 7.6$ years. The mean HbAic value among subjects was $7.9 \pm$ $2.4 \%$. Overall prevalence of poor glycaemic control was 19 (38\%), (Table 1). The prevalence of microbial culture proven UTI was 18 (36\%), while 32 (64\%) were culture negative showing no microbial evidence of UTI (Table 2). UTI was significantly more prevalent in DM patients with poor glycaemic control $14(77.8 \%)$ than in subjects with good glycaemic control 4 (22.2\%) $(\mathrm{P}<0.001)$, (Table 2). Escherichia coli were the most common uropathogen isolated from both test and controls with Enterococcus faecalis being the least (Table 3 ).

Table 1. Prevalence of Poor Glycaemic Control in Test and Controls ${ }^{a}$

\begin{tabular}{lcc}
\hline Subject Groups & HbA1c & P-Value \\
\hline & & $<0.001$ \\
Diabetic group & $7.29 \pm 2.4$ & \\
\hline Healthy controls & $4.5 \pm 1.8$ & \\
\hline a Data are presented as Mean \pm SD.
\end{tabular}

\begin{tabular}{lcccc}
\hline Table 2. Prevalence of UTI at Different Levels of Glycaemic Control \\
\hline UTI & $\begin{array}{c}\text { Good Glycaemic } \\
\text { Control }\end{array}$ & $\begin{array}{c}\text { Poor Glycaemic } \\
\text { Control }\end{array}$ & No. (\%) & P-Value \\
\hline No UTI & 27 & 5 & 32 & $<0.001$ \\
UTI & 14 & 4 & 18 & \\
\hline
\end{tabular}

\begin{tabular}{|c|c|c|}
\hline \multicolumn{3}{|c|}{ a Abbreviation: UTI, Urinary tract infection. } \\
\hline Uropathogen & Diabetes Group & Controls \\
\hline Escherichia coli & 6 & 2 \\
\hline Enterococcus faecalis & 1 & 0 \\
\hline Staphylococcus aureus & 5 & 0 \\
\hline Staphylococcus aureus & 2 & 0 \\
\hline Candida albicans & 4 & 0 \\
\hline
\end{tabular}

\section{Discussion}

The association between poor glycaemic control (HbAlc levels $>7.0 \%$ ) and incidence of urinary tract infection was investigated among asymptomatic diabetic women in Abuja, Nigeria. The prevalence of poor glycaemic control and culture proven UTI was high 19 (38\%) and 18 (36\%) respectively. There was a significant association between poor glycaemic control and the incidence of UTI, this finding concurs with report of previous studies [10-12], but differ from the report of Boyko et al. [13]. HbAlc levels when compared to other risk factors for UTI like kidney size and glomerular filtration rate was found only to constitute a predictor of UTI among a group of 228 women in Pisa Italy [10]. The finding of our study indicates a relationship between prolonged diabetes management and the eventuality of UTI among diabetic women.

Long term effect of diabetes could cause complicated form of UTI which include emphysematous pyelonephritis, emphysematous pyelitis/cystitis and xanthogranulomathous pyelonephritis [14], as such laboratory and clinical diagnosis for UTI should be routinely done in patients on diabetic management. HbA1c is a suitable marker of prolonged treatment for diabetes, it also constitute a marker for treatment progress and an ultimate tool in determining severity and concurrent existence of its complications including nephropathy [9]. The monitoring of HbAic levels among diabetic women is however envisaged.

Sample size was a limitation to this study, this was occasioned by difficulty in obtaining consent from diabetic women attending our centre and cost of laboratory examinations most especially HbAic. Taking into account the representation of pooled subjects (subjects and controls), the result of this study can be said to be tenable.

In conclusion, there was a significant association between poor glycaemic control and UTI among diabetic women studied. There is need for routine screening of all diabetic women for UTI and increased HbA1c levels 
should serve as adjunct marker for compulsory urine microscopy and culture.

\section{Acknowledgements}

Authors appreciate with thanks management of Nena hospital for approving the protocol of this study. Authors also wish to thank subjects used for the study.

\section{Authors' Contributions}

All authors had equal role in design, work, statistical analysis and manuscript writing.

\section{Funding/Support}

This study was personally funded by authors.

\section{References}

1. Funfstuck R, Nicolle LE, Hanefeld M, Naber KG. Urinary tract infection in patients with diabetes mellitus. Clin Nephrol. 2012; 77(1):40-8.

2. Salvatore S, Salvatore S, Cattoni E, Siesto G, Serati M, Sorice P, et al. Urinary tract infections in women. Eur J Obstet Gynecol Reprod Biol. 2011;156(2):131-6.

3. Nicolle LE. Uncomplicated urinary tract infection in adults including uncomplicated pyelonephritis. Urol Clin North Am. 2008; 35(1):1-12.

4. Buell C, Kermah D, Davidson MB. Utility of A1C for diabetes screening in the 19992004 NHANES population. Diabetes Care. 2007;30(9):2233-5.

5. Huisman TH, Martis EA, Dozy A. Chromatography of hemoglobin types on carboxymethylcellulose. J Lab Clin Med.1958;52(2):312-27.

6. Landgraf R. [HbA1c--the gold standard in the assessment of diabetes treatment?]. German, Dtsch Med Wochenschr. 2006;131 Suppl 8:S243-6.

7. Kilpatrick ES, Bloomgarden ZT, Zimmet PZ. Is haemoglobin A1c a step forward for diagnosing diabetes? BMJ. 2009;339:b4432.

8. World Health Organization. Definition and diagnosis of diabetes and intermediate hyperglycemia: A report of WHO/IDF consultation. WHO; 2006. Available from: http://www.who.int/diabetes/publications/diagnosis_diabetes2006/en/.

9. American diabetes association. Executive summary: standards of medical care in diabetes-2009. Diabetes Care. 2009;32 Suppl 1:S6-12.

10. Bonadio M, Boldrini E, Forotti G, Matteucci E, Vigna A, Mori S, et al. Asymptomatic bacteriuria in women with diabetes: influence of metabolic control. Clin Infect Dis. 2004;38(6):e41-5.

11. Peleg AY, Weerarathna T, McCarthy JS, Davis TM. Common infections in diabetes: pathogenesis, management and relationship to glycaemic control. Diabetes Metab Res Rev. 2007;23(1):3-13.

12. Pargavi B, Mekala T, Thamarai Selvi MK. Prevalence of Urinary Tract Infection (UTI) among diabetics patients in Vandavasi, Tamil Nadu, India. Int J Biol Technol. 2011;2(2):42-5.

13. Boyko EJ, Fihn SD, Scholes D, Chen CL, Normand EH, Yarbro P. Diabetes and the risk of acute urinary tract infection among postmenopausal women. Diabetes Care. 2002;25(10):1778-83.

14. Mnif MF, Kamoun M, Kacem FH, Bouaziz Z, Charfi N, Mnif F, et al. Complicated urinary tract infections associated with diabetes mellitus: Pathogenesis, diagnosis and management. Indian J Endocrinol Metab. 2013;17(3):442-5. 